\title{
Formación del discurso en salud mental en la primera mitad del siglo $\mathrm{XX}^{\mathrm{N}}$ \\ Discourse formation in mental health during \\ the first half of the 20th century \\ Formação do discurso em saúde mental \\ no primeiro semestre do século $X X$
}

\author{
Mónica Mojica Perilla, Ps Msc PhD* \\ Laura Del Pilar Cadena Afanador, MD MSP**
}

\begin{abstract}
Resumen
La formación del discurso en salud mental durante la primera mitad del siglo XX tiene en el Movimiento de Higiene Mental y en el Comité Nacional de Higiene Mental sus principales influencias. Como depositarios de un estilo de pensamiento biomédico, los dos entes mencionados tomaron la vocería en el campo de la salud mental, el cual para la época bajo estudio, adolecía de una clara diferenciación conceptual. Con el objeto de comprender la influencia que ejerció este estilo de pensamiento en la formación del discurso en salud mental durante la primera mitad del siglo XX, se desarrolló una reflexión a partir de la revisión de literatura de la época, empleando para tal fin una propuesta teórica que combinó el análisis del discurso de Michel Foucault y la sociología del conocimiento de Ludwik Fleck. Los resultados evidencian una hegemonía del estilo de pensamiento biomédico para abordar la salud mental, representada principalmente en el empleo de la prevención como estrategia de trabajo. De igual forma se constató que fueron los médicos, psiquiatras y salubristas de la época quienes asumieron para sí, como colectivo de pensamiento, la autoridad para hablar y actuar sobre la salud mental de la población, relegando a un segundo plano otros colectivos de pensamiento. [MojicaPerilla M, Cadena-Afanador LP. Formación del discurso en salud mental en la primera mitad del siglo XX. MedUNAB 2014; 16(3):118-126]
\end{abstract}

Palabras clave: Salud mental; Pensamiento; Historia de la medicina; Historia del siglo XX.

\begin{abstract}
The discourse formation in mental health during the first half of the twentieth century has been influenced by the Mental Hygiene Movement and the National Committee for Mental Hygiene. As depositories of the biomedical thinking style, the aforementioned institutions have taken the lead in the field of mental health, which for the period under study suffered from a conceptual differentiation. In order to understand the influence that this thinking style had during the first half of the twentieth century, a review of the literature of the period was developed, using for this purpose a theoretical proposal that combined the discourse analysis of Michel Foucault and the sociology of knowledge of Ludwik Fleck. The results show a dominance of biomedical thinking style to address mental health, represented mainly in the use of prevention as a working strategy, and likewise found that were doctors, psychiatrists and public health professionals who took the time to themselves, as a collective of thinking, the authority to speak and act about the mental health of the population, relegating to the background other groups of thinking. [Mojica-Perilla $M$, Cadena-Afanador LP. Discourse formation in mental health during the first half of the 20th century. MedUNAB 2014; 16(3):118-126]
\end{abstract}

Key Words: Mental health; Thinking; History medicine; History, 20th century.

* Docente, Programa de Psicología, Facultad de Ciencias de la Salud, Universidad Autónoma de Bucaramanga, Colombia.

**Docente, Programa de Medicina, Facultad de Ciencias de la Salud, Universidad Autónoma de Bucaramanga, Colombia.

Correspondencia: Mónica Mojica Perilla E-mail:mmojica@unab.edu.co

Artículo recibido: 2 agosto de 2013, Aceptado: 3 marzo de 2014

I El presente artículo forma parte de los resultados de la investigación titulada "Un análisis arqueológico del discurso sobre salud mental en la primera mitad del siglo XX", financiada por la Universidad Autónoma de Bucaramanga. Colombia. 


\section{Resumo}

A formação do discurso em saúde mental durante a primeira metade do século XX, tem na higiene Movimento Mental e do Comitê Nacional de Higiene Mental suas principais influências. Como repositórios de estilo biomédico de pensar, estas duas entidades levou a voz no campo da saúde mental, o que, para o período em estudo, sofria de uma distinção conceitual clara. A fim de compreender a influência deste estilo de pensamento na formação do discurso sobre a saúde mental durante a primeira metade do século XX, uma revisão literária do período foi desenvolvida, com a utilização de uma proposta teórica do discurso de Michel Foucault combinada com a análise da sociologia do conhecimento de Ludwik Fleck. Os resultados mostram um pensamento estilo

\section{Introducción}

Los desórdenes mentales afectan a millones de personas cada año, y, de no ser tratados, conduce a una enorme carga de sufrimiento, incapacidad y pérdidas económicas. A pesar de las profundas implicaciones que conlleva esta situación, la revisión de la literatura pone de manifiesto que en el ámbito de la salud mental predomina el modelo de enfermedad, y por lo tanto, la gran mayoría de las acciones en dicha área están encaminadas principalmente a la rehabilitación. ${ }^{1-5}$

En el Informe Mundial de la Salud del año 2001, la Organización Mundial de la Salud argumentaba que una definición exhaustiva de salud mental era casi imposible desde una perspectiva transcultural; sin embargo, admitía que el concepto de salud mental era más amplio que la ausencia de trastornos mentales. ${ }^{6}$ A pesar de este reconocimiento, tanto los estudios en salud mental, como las acciones de promoción de salud mental y prevención de los trastornos mentales, siguen estando fuertemente ligadas a una clasificación psicopatológica.

Un claro ejemplo de lo anterior lo constituye el Estudio Nacional de Salud Mental de 2003. Para Urrego Mendoza ${ }^{7}$ se trata de un estudio epidemiológico que estableció prevalencias nacionales para una serie de enfermedades mentales en Colombia, empleando los criterios diagnósticos DSM-IV, valorados mediante la aplicación del instrumento Entrevista Diagnostica Internacional Compuesta. El concepto de salud mental que subyace a dicho estudio es una visión de la misma como ausencia de enfermedad; los resultados expuestos dan cifras sobre incidencia y prevalencia de trastornos mentales, distribuidos por diferentes variables, tales como edad, sexo, estado civil escolaridad, entre otros. Adicionalmente identifica factores de riesgo y protectores para el desarrollo de enfermedades mentales.

Un análisis de los estudios en salud mental realizados en el país desde 1974, incluyendo además el del 2003, evidencia la acepción de salud mental como ausencia de enfermedad hegemonia biomédica para tratar da saúde mental, representado, principalmente, no uso da prevenção como estratégia de trabalho. Da mesma forma, verificou-se que foram os médicos, psiquiatras e profissionais de saúde que tomaram o tempo para si mesmo, como um coletivo de pensamento, a autoridade para falar e agir sobre a saúde mental da população, relegando para segundo plano o pensamento coletivo de outros grupos. [Mónica-Mojica Perilla M, Cadena-Afanador LP. Formação do discurso em saúde mental no primeiro semestre do século XX. MedUNAB 2014; 16(3):118-126]

Palavras chave: Saúde mental; Pensamento; História da medicina; História do século XX

ha sido la que domina el panorama. Sin embargo, dicha postura ontológica no se ha explicitado en la parte conceptual de los trabajos, o se ha descrito una distinta. Estos estudios se han limitado a la identificación de indicadores relacionados con la presencia o ausencia de enfermedades y de factores de riesgo o protectores para desarrollarla. Ha predominado así la perspectiva epistemológica de la epidemiología positivista en el diseño metodológico de los estudios. ${ }^{7}$

La perspectiva previamente citada no es exclusiva de la investigación en salud mental en el país. Una revisión del Informe Mundial de la Salud del año 2001, dedicado al tema, permite constatar que sigue primando un modelo hegemónico de enfermedad, y que por lo tanto lo que se identifica en dichos estudios son prevalencias de trastornos mentales con signos y síntomas claramente establecidos en clasificaciones internacionales. A pesar de los esfuerzos realizados en pro de la salud mental de las poblaciones, lo que se sigue estudiando es la enfermedad mental.

Durante los últimos treinta años la investigación ha contribuido al entendimiento de lo que significa la salud mental; sin embargo, dicha comprensión ha estado restringida ya que gran parte de la evidencia accesible se encuentra en lenguaje inglés y ha sido obtenida en países desarrollados. Se han diseñado diferentes propuestas tendientes a conceptualizar la salud mental fuera de la perspectiva estadística; de esta manera se encuentran algunos trabajos que conceptúan la salud mental como una emoción positiva; otros, la asocian a rasgos de personalidad, en especial con una autoestima positiva. En los últimos tiempos algunos autores incluso la han asociado con el concepto de resiliencia, la cual es entendida como la capacidad para enfrentarse con la adversidad. ${ }^{8}$

Bertolote $^{9}$ afirma que el concepto de salud mental, dada su naturaleza polisémica y sus límites imprecisos, se beneficia de una perspectiva histórica para ser mejor comprendido. Lo que hoy en día es ampliamente entendido como salud mental, puede tener sus orígenes trazados en los desarrollos de la salud pública, la psiquiatría clínica y otras ramas del 
conocimiento. El citado autor sostiene que el concepto de salud mental puede tener sus orígenes en el movimiento de higiene mental estadounidense, iniciado en 1908 por usuarios de los servicios psiquiátricos y profesionales interesados en mejorar las condiciones y la calidad de tratamiento de las personas con desorden mental; de igual manera, afirma que las referencias técnicas a la salud mental como campo o disciplina, no son encontradas sino a partir de 1946, año en el cual la International Health Conference, reunida en New York, decide establecer la World Health Organization (WHO), al tiempo que se funda en Londres la Mental Health Association.

A fin de comprender el papel que ejerció el movimiento de higiene mental en la formación del discurso en salud mental en la primera mitad del siglo XX, así como su posterior posicionamiento como tema prioritario en la agenda de la Organización Mundial de la Salud, se presenta una revisión de documentos de la época que fueron abordados a partir de la propuesta de análisis arqueológico de Foucault ${ }^{10-15}$ combinada con la vertiente de la sociología del conocimiento atribuida a Fleck; ${ }^{16-21}$ en la recopilación de la masa documental se atendió a parámetros temáticos, lingüísticos y cronológicos. Un acercamiento a la formación de éste discurso permitirá comprender la lógica que poseen las propuestas de entes como la Organización Mundial de la Salud con relación al trabajo en el campo de la salud mental, las cuales en definitiva influyen de manera decisiva tanto en las labores de investigación como en las de intervención. No es suficiente con reconocer la existencia de un cierto pragmatismo teórico en los documentos de los anteriores organismos, hace falta dilucidar los orígenes de este rasgo para así poder dar voz a los más diversos discursos que existen en el campo de la salud mental, los cuales han sido relegados por el discurso oficial que en definitiva permea la propuesta e implementación de políticas publicas, desconociendo de esta manera la diversa y mutante realidad del ser humano.

\section{Conformación del movimiento de higiene mental y el comité nacional de higiene mental}

La historia sobre el discurso en salud mental en el período bajo estudio, está ligada a la historia del Mental Hygiene Movement (en adelante Movimiento de Higiene Mental) así como a la del National Committee for Mental Hygiene (en adelante Comité Nacional), liderados en Estados Unidos por Cliffor Beers, ciudadano del común que tras pasar tres años por tres instituciones psiquiátricas diferentes, se da a la tarea de escribir un libro autobiográfico, publicado en $1908^{22}$, en el que no sólo relata su terrible experiencia durante sus años de internación, sino que también promueve el análisis y una reforma al sistema de atención a los sujetos que padecían de enfermedades mentales. En este sentido proponía, con una visión más humanitaria, que la atención a los enfermos mentales debía alejarse de aquellas prácticas en las que el uso de la violencia tomaba lugar, lo que requería en principio abrir la discusión al público en general, así como promover investigaciones que dieran cuenta de las causas de la enfermedad mental y a futuro crear sistemas de prevención de dichas enfermedades.

Tres prominentes académicos de la época, entre otros muchos personajes públicos, apoyaron la iniciativa de Beers; en primer lugar William James, psicólogo catedrático de Harvard quien escribió la introducción de la obra. Adicionalmente escribió cartas de presentación que le permitieron a Beers contactar personas influyentes.

Adolf Meyer, psiquiatra reconocido de la época y director del Pathological Institute of New York State Hospital, percibió en los escritos de Beers una confluencia de la psiquiatría con la conciencia social de los problemas encontrados en el tratamiento de los enfermos mentales. Para Meyer, la última parte del libro, referida a las propuestas de acción, requería de una modificación, para lo cual haciendo uso de su experiencia y juicio científico, sugirió a Beers replantear su propuesta e inclinar su énfasis hacia objetivos positivos de prevención, así como de promoción de una conciencia de salud social e individual, para lo cual sugirió el término "Hygiene Mental". ${ }^{23}$

Con respecto a la participación de Meyer en el surgimiento del Comité Nacional en 1909, es importante destacar el hecho de que fue él junto con James y otros asesores, quienes sugirieron a Beers empezar con un movimiento de carácter regional, dando paso así al nacimiento de la Connecticut Society for Mental Health, fundada en 1908, para posteriormente en 1909 fundar el comité nacional. ${ }^{24}$

La formación médica de Meyer ejerce una clara influencia en el desarrollo y consolidación del movimiento de higiene mental. Para este personaje, la psiquiatría debía descansar en una concepción biológica y reiteraba que "We must...accept the statement that all mental activity must have its physiological side and its anatomical substratum" (pág 29). Esta visión evidencia un estilo de pensamiento biomédico en el que la salud era vista como la cara opuesta de la enfermedad, y por lo tanto la ausencia de signos y síntomas asociados a la segunda definirían el estado de salud. Meyer argumentó la necesidad de basar las propuestas del Comité Nacional en los resultados de la investigación científica, apoyado en la creencia de que las causas de la enfermedad mental tenían sus raíces en la interacción entre la biología y la historia de vida, comenzando así una aproximación biográfica para estudiar los pacientes con enfermedades mentales, la cual debería proporcionar una base científica a los esfuerzos del movimiento de higiene mental. ${ }^{26}$

Un tercer personaje se convertiría en protagonista esencial de la iniciativa de Beers. Thomas Salmon, primer director científico del Comité Nacional y médico psiquiatra de 
formación, quien fuera funcionario del United States Public Health Service antes de su llegada al Comité, le imprimió al movimiento una mirada desde la Salud Pública. Su trabajo permitió que las ideas reformistas de Beers y el trabajo profesionalizante de Meyer se conjugaran en una perspectiva de trabajo aplicado orientada desde la Salud Pública, disciplina que para inicios del Siglo XX concentraba sus esfuerzos en tareas de prevención, visión fuertemente influenciada por los avances de la biología y la medicina en el tema de las enfermedades infecciosas. En este sentido, es importante destacar el hecho de que fue Salmon el más interesado en este enfoque, dadas las implicaciones que para el financiamiento del Comité representaba sumarse a los esfuerzos preventivos de la Salud Pública estadounidense de principios de siglo, esfuerzos que contaban con el apoyo económico de diferentes organizaciones filantrópicas, en especial la Fundación Rockefeller, quien financió actividades del Comité Nacional. Por otra parte, es pertinente recordar que Salmon manifestó igualmente un interés particular en el tema de la investigación, que para el caso del Comité Nacional debía inicialmente estar dirigida a la recopilación de estadísticas sobre la enfermedad mental en Estados Unidos.

Como consecuencia de la posición de Salmon en el Comité y sus fuertes nexos con la Fundación Rockefeller, agencia financiadora del mismo, el Comité Nacional y el Movimiento de Higiene mental que lo sustentaba, recibieron reconocimiento social y científico, determinantes claves en su proceso de legitimación ante la sociedad académica estadounidense.

De forma paralela a la creación del Comité Nacional se dio paso a la apertura de otros comités de carácter estatal y local. Es así como para 1909 se crea la segunda sociedad estatal en el Estado de Illinois y para 1910 la tercera en el Estado de Nueva York. Para 1930 había cerca de cincuenta (50) asociaciones del mismo tipo a lo largo del territorio estadounidense, así como algunas internacionales, como el caso de la Liga Francesa de Higiene Mental. Para inicios de los años 40 este número llegaría alrededor de 200. Todas estas asociaciones a pesar de actuar de forma independiente y de contar con diferentes estructuras y programas de trabajo, guardaban una estrecha relación entre sí y con el Comité Nacional; sin embargo, era evidente aún la apatía del público en general hacia este trabajo. ${ }^{27}$

Caso contrario a lo sucedido con el público general, el interés de diferentes profesionales hacia el movimiento fue creciendo con el pasar de los años, tal y como lo plantea Ridenour: ${ }^{27}$

One of the first signs of speedup in the momentum of the mental hygiene movement might have been observed in the 1930's, when workers in many different professions began to take keen interest in the new ideas. Much of the leadership came from the so-called "core" professions, which included psychiatrists, psychiatric social workers, and clinical psychologists-those whose professions by definition were concerned with mental illness and the mentally ill (p. 1096).

Para 1919 el sueño de Beers de crear una organización nacional se había expandido por todo Estados Unidos, Canadá y algunos países de Europa, fue en este mismo año cuando se crea el International Committee for Mental Hygiene (ICMH por sus siglas en inglés) cuyo protagonismo fue evidente con la organización del Primer Congreso Internacional de Higiene Mental, celebrado en Washington entre el 5 y el 10 de mayo de 1930. Con aproximadamente 3000 asistentes, el congreso se convirtió en un espacio donde se reunieron los protagonistas no sólo del Movimiento de Higiene Mental y del Comité Nacional e Internacional, sino también otras personas que trabajaban en el campo de la higiene mental. ${ }^{28}$

El Segundo Congreso Internacional de Higiene Mental tuvo lugar en Paris, aunque estaba programado para 1936 la recesión económica impidió que se realizara ese año y se pasó para 1937. Para ese momento la internacionalización del Movimiento de Higiene Mental fue aún más evidente, sin embargo, el inicio de la guerra marcaría una interrupción considerable al auge de su trabajo, que sería nuevamente retomado en el período de la posguerra.

En 1946 John Rowlings Rees fue encargado por la Association for Mental Health of England and Wales de organizar el tercer congreso internacional de higiene mental; para este fin, Rees obtuvo el patrocinio del International Committee on Mental Hygiene y de la American Psychiatric Association, con este último apoyo se lograba un importante respaldo de la comunidad de psiquiatras de Estados Unidos, lo que finalmente validaba el impacto del trabajo que venían desarrollando el Comité Nacional y el Internacional. Bajo la presidencia de Rees, el congreso tuvo lugar en Londres en 1948, y fue en realidad la conjunción de tres conferencias internacionales: 1. Child Psychiatry. (Theme: Personality development in its individual and social aspects with special reference to aggression.); 2. Medical Psychotherapy. (Theme: Guilt.); 3. Mental Hygiene. (Theme: Mental Health and World Citizenship). ${ }^{29}$

Bajo estas condiciones el Tercer Congreso Internacional de Higiene Mental se transformó en el Primer Congreso Internacional de Salud Mental. En la sesión de clausura del evento, Rees anunciaría oficialmente la creación de la World Federation for Mental Health-WFMH (Federación Mundial de Salud Mental), organización que daría continuidad al trabajo del Comité Internacional y se convertiría en la agencia oficial de consulta voluntaria en el ámbito de la salud mental para la UNESCO y la Organización Mundial de la Salud (OMS). A este respecto, el Dr. Brock Chisholm, Director General de la OMS, informó que la Asamblea Mundial de la Salud había dado 
instrucciones al Comité Ejecutivo de la OMS para que tomara las acciones, dentro de la capacidad financiera posible, que fueran recomendadas tanto por el Congreso Mundial de Salud Mental como por la World Federation for Mental Health. ${ }^{29-30}$

Bajo las condiciones históricas del Movimiento de Higiene Mental y del Comité Nacional previamente descritas, transitó el discurso sobre la salud mental durante la primera mitad del siglo XX. En este punto es importante destacar el hecho que para la época no existía una diferenciación clara entre los términos higiene mental y salud mental, de forma tal que la gran mayoría de autores consultados empleaban de manera indistinta los dos, pero enfocados siempre desde la lógica de la prevención. Recordemos que para Fleck no existe una generación espontánea de los conocimientos, el surgimiento y transformación de los mismos posee una determinación socio-histórica que va más allá de la misma cientificidad y deja al descubierto que, efectivamente, no existe ningún tipo de conocimiento, concepto o teoría que sea totalmente objetivo y libre de los matices que le imprime el contexto social e histórico en los cuales surgieron.

Para este caso en particular, la influencia del colectivo de pensamiento conformado por médicos y psiquiatras fue determinante, sin embargo, es pertinente recordar cómo la medicina logró un triunfo relativo sobre las enfermedades infecciosas, ya que este hecho marcaría un punto fundamental en la historia y la práctica de la salud pública, disciplina que desde sus inicios influyó directamente en las actividades del Comité Nacional y del Movimiento de Higiene Mental.

La transición de la higiene pública hacia la salud pública se encuentra enmarcada en lo que fue la transformación misma de la medicina, la que trajo consigo una nueva forma de entender la enfermedad. La teoría miasmática, dominante hasta mediados del siglo XIX, se vio relegada por lo que se ha denominado la bacteriologización. De la mano de ella llegaron nuevos descubrimientos que no se encontraban alejados de los asuntos políticos y económicos de la época, al contrario, estos últimos determinaron considerablemente tanto los progresos que en materia de medicina se hacían, como las aplicaciones de los mismos dentro de un marco de salud pública. La teoría bacteriológica simplificaba en gran medida el trabajo de prevención y tratamiento de las enfermedades, ya que al considerarse que para cada enfermedad existía un único agente causal (la bacteria), las medidas de higiene pública se tornaban bastante simples: evitar que los individuos entraran en contacto con ella. ${ }^{19}$

Es así como la noción de prevención irrumpe con toda su fuerza en el campo de la salud pública en general y en el de la medicina en particular, y este hecho que tuvo condicionantes históricos, sociales, políticos y económicos, determinaría el discurso en salud mental durante el período estudiado.

\section{Noción de prevención en el discurso sobre salud mental}

Tanto Salmon como Meyer concordaban en la necesidad de dar un enfoque preventivo al trabajo del Comité, por lo que proponían una agenda de acciones que iban más allá de la propuesta por Beers en relación a las reformas institucionales que debían hacerse en torno a la atención de las personas que padecían algún trastorno mental. Dicho enfoque preventivo debía estar basado en una aproximación desde la salud pública y con énfasis en atención a la comunidad. $^{31}$

Este fuerte enfoque en la salud pública que caracterizó desde sus inicios el trabajo del Comité, queda plasmado en la siguiente afirmación: "When the School ${ }^{1}$ was founded in 1916, the country had only just begun to see mental health within the context of public health", publicada en el prólogo del magazin de la John Hopkins Bloomberg School of Public Health en el número de otoño de 2003.

El énfasis biologicista de la época, aplicable también al caso de la higiene mental, sustentaba una visión según la cual los desórdenes mentales estaban asociados a perturbaciones en el sistema nervioso, por lo tanto para los higienistas mentales las causas de la enfermedad mental poseían un sustrato eminentemente físico, por lo que era posible asumir desde esta lógica de pensamiento que la ausencia de locura necesariamente estaría asociada a una buena salud física. La anterior apreciación juega un papel protagónico en el enfoque de prevención propuesto para el trabajo en el campo de la higiene mental, dado que las acciones de profilaxis propuestas para prevenir la aparición de enfermedades mentales estaban asociadas a temas tales como las condiciones de habitación, de alimentación, el ejercicio físico y el deporte. ${ }^{24}$

La noción de prevención estaba inmersa en la higiene mental, de forma tal que para quienes entraron a formar parte de los diferentes comités estatales y nacionales, no existía discusión en torno a que las actividades asociadas a la misma debían estar a cargo de departamentos de salud pública. Esta visión fue fuertemente influenciada por el colectivo de pensamiento conformado por médicos y psiquiatras, quienes desde los inicios del movimiento de higiene mental jugaron un rol protagónico. ${ }^{32-33}$ En este sentido es pertinente destacar el hecho de que para esta misma época, la psicología como disciplina estaba inclinada al desarrollo de actividades de evaluación

1 Hace referencia a la fundación de la John Hopkins School of Hygiene and Public Health, cuyo decano William H. Welch, estuvo presente en la formación de Comité Nacional en 1909. Para la socialización del prospecto de creación de dicha Escuela, que fue presentado oficialmente a la Fundación Rockefeller en 1915, Welch y Witcliffe Rose incluirían la higiene mental en el plan de estudios como parte de los cursos que se impartirían. 
psicológica más que a la intervención misma, por lo cual el campo de la prevención, y aún el de la intervención en el caso de las enfermedades mentales, era eminentemente médico, por eso,fue precisamente éste colectivo el que lideraría durante la primera mitad del siglo XX tanto el discurso como las acciones en lo que se denominó la higiene mental.

Este énfasis en la prevención como estrategia de trabajo es herencia de un estilo de pensamiento para el que cada enfermedad debe poseer una causa y por lo tanto al identificarla se pueden generar estrategias para que no actúe en el individuo, previniendo así la aparición de la enfermedad y conservando la salud. Esta misma lógica fue aplicable al caso de la enfermedad mental. Sin embargo, con las restricciones que imponían los avances en el conocimiento sobre la etiología de la misma, era claro que las acciones de higiene propuestas no podrían cumplir completamente con el objetivo de la prevención de enfermedades mentales.

La adopción de este estilo de pensamiento excluyó de la discusión el análisis teórico de lo que se entendía por salud mental, puesto que lo primordial desde la visión preventiva era precisamente eso: prevenir la aparición de enfermedades mentales tal y como se hacía para el caso de la enfermedades físicas, de forma tal que si las primeras no hacían su aparición se estaba asegurando la buena salud mental de la población. Se puede apreciar así cómo el énfasis del Movimiento de Higiene Mental y del Comité Nacional estaba centrado sobre la enfermedad mental y no sobre la salud mental.

El anterior estilo de pensamiento era compartido por los profesionales de la medicina que se desempañaban como psiquiatras o como salubristas, lo que nos coloca frente a un colectivo de pensamiento legitimado científica y socialmente, que para la época ejercía una hegemonía en relación al discurso sobre la salud y la enfermedad mental. Esta hegemonía se veía materializada en la metodología que se empleaba para estudiar e intervenir sobre aquellas, una metodología que respondía a un modelo epistemológico positivista, el cual quedaba reflejado en los artículos que durante la época se escribían sobre el campo de la salud mental.

\section{Legitimación del discurso oficial en salud mental}

El discurso en salud mental formado durante la primera mitad del siglo XX tuvo una fuerte influencia del colectivo de pensamiento conformado por médicos y psiquiatras. Este discurso, disperso en los términos de Foucault, desembocaría para finales de los años 40 en una propuesta de definición de salud mental realizada por el Comité de Expertos en Higiene Mental, equipo consultor encargado por la recién creada Organización Mundial de la Salud para: "asesorar en los asuntos relativos al cumplimiento de las decisiones de la asamblea acerca del programa para 1950 y formular recomendaciones para el programa de 1951". ${ }^{34}$

La primera reunión de este Comité tuvo lugar en Ginebra, del 29 de agosto al 2 de septiembre de 1949, un año después de la entrada en vigor de la constitución de la OMS, la cual se había declarado en 1946. En el reporte oficial de dicha reunión, ${ }^{34}$ escrito originalmente en inglés, se emplea el término "mental health", sin embargo, en la versión de la OMS en lengua castellana se empleó el término "higiene mental". Puede que esta particularidad sea semántica, y refleje simplemente la tradición presente durante casi cincuenta años del término que se había acuñado en Estados Unidos, sin embargo, al menos en el informe de la primera reunión, la distinción entre higiene mental y salud mental aún no estaba clara. La lectura del citado reporte deja entrever que hasta ese momento la Comisión no había realizado una diferenciación de términos, al punto tal que equipara el fomento de la higiene mental con el fomento de la salud mental; de igual forma, tal y como había sido la tradición hasta ese momento, proponían la prevención como principal estrategia de trabajo: "El Comité estima...que sólo mediante la aplicación en el aspecto preventivo de los conocimientos psiquiátricos será posible encontrar la solución a los problemas de higiene mental". ${ }^{34}$ No es de extrañar esta posición si tomamos en cuenta que la totalidad de los miembros principales de éste Comité eran médicos psiquiatras, por lo cual su estilo de pensamiento fue el que predominó en las recomendaciones que hicieran a la OMS.

En relación a la composición del Comité, el informe recomienda que el núcleo permanente en pleno esté integrado por psiquiatras generales, dejando la participación de otros profesionales para casos puntuales en los que se requiriera su colaboración en la elaboración de programas de higiene mental. Al final de este primer informe, el Comité hace un resumen sobre las recomendaciones plasmadas en el cuerpo de dicho trabajo, las cuales serían presentadas posteriormente a la OMS. Dichas recomendaciones abarcan numerosos temas, que fueron clasificados en las siguientes subsecciones: Principios y orden de prioridad en las actividades de higiene mental; educación; enfermeras; becas; suministro de publicaciones técnicas a los Gobiernos; educación sanitaria del público; recopilación de información; servicios de demostración y asesoramiento; investigación; alcoholismo y toxicomanía; higiene maternoinfantil; enfermedades venéreas; clasificación internacional de enfermedades; estudios de morbilidad; unificación de farmacopeas; cooperación con las Naciones Unidas; cooperación con los organismos especializados; cooperación con organismos no gubernamentales y Comité de Higiene Mental.

Al revisar el informe en cuestión, la atención se centró en las siguientes recomendaciones. La primera de ellas se 
encuentra en la sección de principios, y propone que: " $L a$ OMS debe aceptar la aplicación preventiva de los conocimientos psiquiátricos como el principio más importante de un programa mundial de higiene mental”. Es clara así una continuidad de la hegemonía del colectivo de pensamiento conformado por los médicos psiquiatras que ya se ha descrito a lo largo del presente documento, con la consiguiente trasposición de su estilo de pensamiento al trabajo en el campo de la salud mental.

En relación a la subsección de investigación, el Comité propuso entre otros temas, fomentar la investigación en: Etiología y tratamiento de los trastornos psiquiátricos; efectos que producen en la salud mental los cambios rápidos en las características culturales y los medios para prevenir y mitigar los efectos nocivos de dichos cambios; igualmente en otra subsección propone que se deben desarrollar estudios de morbilidad psiquiátrica en distintas partes del mundo. Con relación a este tema, se destaca el hecho que con algunas modificaciones, en la actualidad la OMS continúa impulsando investigación en estos mismos temas.

En la subsección que corresponde a la Clasificación Internacional de Enfermedades (CIE por sus siglas en español) el Comité propuso que se debía compilar un glosario de definiciones descriptivas para la parte del manual que se refiriera específicamente a los trastornos mentales, neuróticos y de personalidad; igualmente sugería que se debía informar en el marco del Congreso Mundial de Psiquiatría de 1950 la existencia de dicho manual, a fin de lograr la cooperación de los psiquiatras en la utilización del mismo. A la fecha las versiones actualizadas del CIE son empleadas a nivel mundial, teniendo como principal objetivo el permitir comparar las estadísticas relacionados con morbilidad y mortalidad tanto a nivel nacional como internacional.

En el informe de la Segunda Reunión del Comité de Expertos en Higiene Mental, reunido en Ginebra del 11 al 16 de septiembre de 1950, se encuentra una distinción explícita de los términos salud mental e higiene mental. Antes de presentar el informe general, y bajo el título de definiciones, el Comité afirma:

La salud mental, tal como la comprende el comité, es influenciada por factores tanto sociales como biológicos. No es una condición estática, sino sujeta a variaciones y fluctuaciones de cierta intensidad; el concepto del comité implica la capacidad de un individuo para establecer relaciones armoniosas con otros y para participar en modificaciones de su ambiente físico y social o de contribuir con ello de modo constructivo. Implica también su capacidad de obtener una satisfacción armoniosa y equilibrada de sus propios impulsos instintivos, potencialmente en conflicto; armoniosa porque culmina en una síntesis integrada, más bien que en la abstención de la satisfacción de ciertas tendencias instintivas, como fin de evitar la frustración de otras. ${ }^{35}$
En relación a la higiene mental afirma:

Es igualmente necesario explicar en qué forma se usa en este informe el término "higiene mental", pues la palabra se emplea a menudo en sentido eufemístico para designar el tratamiento psiquiátrico temprano... En este informe el término se emplea en un sentido estricto y literal, análogo al modo en que se usa el término general de "higiene" en la práctica de la salud pública. Para el Comité, entonces, la higiene mental consiste en las actividades y técnicas que promueven y mantiene la salud mental. ${ }^{35}$

Queda abonado de esta forma el terreno para que varios años después la OMS propusiera, no una definición como tal, mas si una apreciación de lo que a su entender es la salud mental:

Salud mental es más que la mera ausencia de trastornos mentales. La dimensión positiva de la salud mental ha sido subrayada en la definición de salud de la OMS, tal cual consta en la constitución misma: «La salud es un estado de completo bienestar físico, mental y social y no solamente la ausencia de afecciones o enfermedades». Los conceptos de salud mental incluyen bienestar subjetivo, autonomía, competencia, dependencia intergeneracional y reconocimiento de la habilidad de realizarse intelectual y emocionalmente. También ha sido definido como un estado de bienestar por medio del cual los individuos reconocen sus habilidades, son capaces de hacer frente al estrés normal de la vida, trabajar de forma productiva y fructífera, y contribuir a sus comunidades. Salud mental se refiere a la posibilidad de acrecentar la competencia de los individuos y comunidades y permitirles alcanzar sus propios objetivos. Salud mental es materia de interés para todos, y no sólo para aquellos afectados por un trastorno mental. ${ }^{36}$

Llegamos así a una definición de salud mental que es propuesta fuera de los círculos académicos, pero que se encuentra legitimada en tanto proviene del organismo rector para temas de salud a nivel mundial. La lectura de los diferentes documentos oficiales de la OMS permite entrever que dicha organización no tiene filiaciones teóricas y/o epistemológicas específicas, en ocasiones queda la sensación de un vacío conceptual en sus propuestas, que por lo general se encuentran más asociadas a la implementación de acciones sanitarias tendientes a prevenir la enfermedad ("física y/o mental") y garantizar un adecuado nivel de salud ("física y/o mental"). Pero independientemente de esta particularidad, el hecho es que precisamente es la OMS, como organismo supranacional, quien establece una serie de recomendaciones que son seguidas por los estados miembros al momento del diseño y puesta en marcha de políticas, planes y programas en salud, para este caso en salud mental. Como organismo comprometido con la salud de la población a nivel mundial, no propició una discusión teórica ni conceptual del término salud mental, tal vez porque ese no es ni ha sido su interés, sin embargo, sus recomendaciones son esenciales y tenidas en cuenta cuando los estados planean sus acciones en salud. 
En definitiva, para el período en estudio no existió un trabajo académico que diera cuenta de discusiones y análisis epistemológicos, teóricos y conceptuales en relación a la salud mental, por el contrario, fue un organismo no académico el que al final propusiera una delimitación del campo de la salud mental. Sin embargo, esta delimitación, que se vislumbró desde el Segundo Informe del Comité de Expertos en Higiene Mental, tiene una clara influencia del colectivo de pensamiento conformado por los médicos psiquiatras, lo que al final sería decisivo en las propuestas futuras de la OMS en relación a la salud mental como objeto de estudio.

Ahora bien, cuando de pensar en las implicaciones de los resultados previamente descritos se trata, es necesario afirmar que el solo reconocer la inexistencia de una discusión teórica y epistemológica durante el surgimiento y consolidación de lo que hoy conocemos como la versión oficial del término salud mental no es suficiente, ya que dejaría por fuera del tintero una necesaria reflexión sobre este estado actual de las cosas y qué camino se ha recorrido para llegar a él. El campo de conocimientos y prácticas en salud mental continúa en disputa, y son muchas las áreas de saber que se encuentran insertas en el mismo, sin embargo es aquel discurso oficial el que sigue permeando las propuestas y planes de trabajo, relegando a un segundo plano la potencialidad que representa asumir la discusión de lo que entendemos por salud mental. No es solo el reconocer la existencia de este discurso y de qué colectivos de pensamiento lo siguen liderando, la reflexión debe ir más allá en el sentido de propiciar acercamientos desde diversas miradas de la realidad a fin de construir un conocimiento que efectivamente intente superar la visión reduccionista de la salud mental como ausencia de enfermedad mental, posición en la que se endilga la responsabilidad de su cuidado casi que de forma exclusiva a cada individuo, liberando así de responsabilidades a una sociedad y a sus estados. Esta mirada desde diferentes disciplinas científicas y desde diversas posiciones epistemológicas potencializará una discusión profunda de lo que hoy entendemos por salud mental, lo cual necesariamente deberá verse reflejado en las acciones encaminadas a preservar la misma.

\section{Conflicto de intereses}

Las autoras manifiestan que no tienen ningún conflicto de interés con la publicación de este trabajo.

\section{Referencias}

1. Caplan G. Aspectos preventivos en salud mental. 1a edición. Barcelona: Paidos; 1993.

2. De Jong A, Gile R, Ten Horn G.H. The WHO International Classification of Mental Health Care. Ginebra: WHO; 1988.
3. De la Fuente J.R. Hacia dónde va la investigación en psiquiatría?. Salud Mental 2005; 18(2):55-59. [Acceso 22 de julio de 2009]. Disponible en:http://www.inprfcd.org.mx/pdf/sm1802/sm180255.pdf

4. Fernández Rios L, Buela-Casal G. El concepto de salud enfermedad. En: Buela-Casal G; Fernández Rois L, Carrasco T.J. (Eds). Psicología preventiva. Avances recientes en técnicas y programas de prevención. Madrid: Pirámide; 1997.

5. Sadock B.J, Kaplan H.I. Clasificación de los trastornos mentales. En: Kaplan H, Sadock B.J, (Eds). Tratado de Psiquiatría. 6 edición. Buenos Aires: Intermédica; 1997.

6. World Health Organization. The world health report 2001. Mental health: new understanding, new hope. Geneve: WHO; 2001.

7. Urrego Mendoza Z. Reflexiones en torno al análisis de la situación de salud mental en Colombia, 1974-2004. Revista Colombiana de Psiquiatría 2007; 36(2): 307-319. [Acceso 25 de julio de 2009]. Disponible en: http://www.scielo.org.co/pdf/rcp/v36n2/v36n2a10.pdf

8. World Health Organization. Promoting mental health: concepts, emerging evidence, practice. Geneve: WHO; 2005.

9. Bertolote J.M. The roots of the concept of mental health. World Psychiatry 2008; 7: 113-116. [Acceso 22 de noviembre de 2009]. Disponible en: http:// onlinelibrary. wiley.com/doi/10.1002/j.2051-5545.2008.tb00172.x/pdf

10. Foucault M. La arqueología del saber. México: Siglo XXI Editores; 1970.

11. Arouca S. O dilema preventivista. Contribuicąo para a compreensao e crifica da medicina preventiva. Sao Paulo: Editora UNESP. Rio de Janeiro: Editora Fiocruz; 2003.

12. Balza R. Aportes de la filosofía a una historia critica de la epistéme científica. Ágora 2005; 8(15). [Acceso 09 de agosto de 2009]. Disponible en: http://www.saber.ula.ve/ handle/123456789/17621

13. Machado R. Foucault: A ciência e o saber. Rio de Janeiro: Jorge Zahar Editor; 2006.

14. Nunes E. D. Pequeño guia vocábulario para a utilizacao da história arqueológica como instrumento de pesquisa qualitativa. Interface. 2002; 6(10): 125-134. [Acceso 10 de mayo de 2009]. Disponible en: http://www.scielo.br/ pdf/icse/v6n10/16.pdf

15. Teixeira de Carvalho A. O processo de produção discursiva: uma visão da contribuição de Michel Foucault ao debate epistemológico. 2006. Disponible en: http://www2.uerj.br/ revispsi/v1n1/artigos/artigo9.html

16. Fleck L. La génesis y el desarrollo de un hecho científico. Introducción a la teoría del estilo de pensamiento y el colectivo de pensamiento. Madrid:Alianza Editorial. 1986.

17. Löwy I, Ludwik Fleck e a presente história das ciências. Manguinhos. 1994; 1(1): 7-18. [Acceso 15 de septiembre de 2009]. Disponible en: http://www.scielo.br/pdf/hcsm/ v1n1/a03v01n1.pdf

18. Christiansen Renaud M.L. La epistemología comparada y su impacto sobre la historiografía de la psicología. Revista Electrónica Nova Scientia. 2009; 2(1): 117-129. [Acceso 08 de julio de 2009]. Disponible en: http://dialnet.unirioja.es/servlet/articulo?codigo=3314302

19. Mojica Perilla M. Surgimiento y transformación de los conceptos de salud y enfermedad en la epidemiologia crítica latinoamericana: una perspectiva desde el discurso de Jaime Breilh y Naomar de Almeida-Filho. Tesis de Doctorado en Salud Pública. Facultad de Medicina. Universidad Nacional de Colombia. Bogota-Colombia. 2009 
20. Schafer L, Schnelle T. Introducción: Los fundamentos de la visión sociológica de Ludwik Fleck. En: Fleck L. La génesis y el desarrollo de un hecho científico. Introducción a la teoría del estilo de pensamiento y el colectivo de pensamiento. Madrid:Alianza Editorial. 1986.

21. Pfuetzenreiter M.R. Epistemologia de Ludwik Fleck como referencial para a pesquisa nas ciências aplicadas. Episteme 2003; 16: 111-135. [Acceso 17 de febrero de 2009]. Disponible en:http://paginas.cav.udesc.br/ a2mrp/public_html/Textos\%20Marcia/episteme16_artig o_pfuetzenreiter.pdf

22. Beers Clifford. A mind that found itself. New York: Longmans, Green and Company. 1908.

23. Campos da Silva M.L. "Psychiatric social work": da higiene mental à psicanálise. Dissertação apresentada ao Departamento de Serviço social da PUC/RJ como parte dos requisitos para obtenção do título de Mestre em Serviço Social. Departamento de Serviço Social Pontifícia Universidade Católica do Rio de Janeiro. 1993.

24. Mateus Steffens C, Rojas Gualdrón D. Del tratamiento moral de las enfermedades mentales a la salud mental comunitaria. Una aproximación histórico-epistemológica al concepto de salud mental durante el período de higiene mental. Trabajo de Grado de Psicología inédito. Facultad de Ciencias de la Salud. Universidad Autónoma de Bucaramanga. Bucaramanga. Colombia. 2009.

25. Smoyak S.A. The history, economics, and financing of mental health care. A Journal of Psychosocial Nursing \& Mental Health Services. 2000; 38(10): 26-37.

26. Mandell W. (s.f.). The Realization of an Idea. Disponible en: http://www.jhsph.edu/departments/mentalhealth/ about/origins.html

27. Ridenour N. The mental health movement. En: Deutsch, A. \& Fishman, H. (Eds). The encyclopedia of mental health, 1963; 3:1091-1102. New York, Franklin Watts.
28. Public Health Reports. First Health First International Mental Hygiene Congress to Be Held in Washington, D. C., May 5-10, 1930. Public Health Reports. 1930; 45(2): 69-70.

29. Canadian Journal of Psychology. International Congress on Mental Health: London, England, August 11-21, 1948. Canadian Journal of Psychology/Revue canadienne de psychologie. 1948; 2(2): 88-89.

30. The British Medical Journal. International Congress On Mental Health. The British Medical Journal. 1948; 2(4573): 433-437.

31. Jhon Hopkins Bloomberg School of Public Health. Prologues of Public Health. "Meeting on the same errand": Origins of Mental Hygiene. The Magazine of the Johns Hopkins Bloomberg School of Public Health. 2003. Disponible en: http://magazine.jhsph.edu/2003/fall/ prologues/page2.html

32. Myers, G. The California State Mental Hygiene Survey. California and Western Medicine 1930; 33(6): 872-876. [Acceso 10 de octubre de 2012]. Disponible en:http://www.ncbi.nlm.nih.gov/pmc/articles/PMC16576 31/pdf/calwestmed00466-0024.pdf

33. Ackerly S. Trends in Mental Hygiene: An Interpretation. Review of Educational Research 1943; 13(5): 416-421. [Acceso 6 de octubre de 2012]. Disponible en: http://www.jstor.org/stable/1168388

34. World Health Organization. Comité de Expertos en Higiene Mental. Informe de la Primera Reunión. Ginebra, 29 de agosto al 2 de septiembre de 1949.

35. World Health Organization. Comité de Expertos en Higiene Mental. Informe de la Segunda Reunión. Ginebra, 11 al 16 de septiembre de 1950.

36. Organización Mundial de la Salud. Invertir en salud mental. Departamento de salud Mental y Abuso de Sustancias. Ginebra. 2004. 